\title{
Toxicological evaluation of the nicotine on CA1 and protective effects of curcuma longa: An experimental study
}

\author{
Mohammad Reza Salahshoor ${ }^{1}$, Shiva Roshankhah ${ }^{1}$, Babak Arji Roudsari ${ }^{1}$, Cyrus Jalili ${ }^{2, *}$
}

${ }^{1}$ Department of Anatomical Sciences, Medical School, Kermanshah University of Medical Sciences, Kermanshah, Iran

${ }^{2}$ Medical Biology Research Center, Kermanshah University of Medical Sciences, Kermanshah, Iran

Correspondence

Cyrus Jalili, Medical Biology Research Center, Kermanshah University of Medical Sciences, Kermanshah, Iran

Email: cjalili@yahoo.com

History

- Received: May 10, 2019

- Accepted: Aug 10, 2019

- Published: Sept 23, 2019

DOI :

https://doi.org/10.15419/bmrat.v6i9.565

\section{Check for updates}

\section{Copyright}

(c) Biomedpress. This is an openaccess article distributed under the terms of the Creative Commons Attribution 4.0 International license.

\begin{abstract}
Introduction: Nicotine is the most important alkaloid compound in tobacco and is a major risk factor in the development of functional disorders of several organ systems. Some plants produce Curcuma longa (curcumin), which has antioxidant and neuro-protective properties. Methods: This study was designed to evaluate the therapeutic effects of curcumin against nicotine injury on the hippocampus CA1 region of rats. In this study, 48 male rats were randomly assigned to eight groups: Normal control (saline) group, Nicotine control group $(0.5 \mathrm{mg} / \mathrm{kg}$ ); Curcumin groups (10, 30, and $60 \mathrm{mg} / \mathrm{kg}$ ) and Nicotine + Curcumin groups (10,30, and $60 \mathrm{mg} / \mathrm{kg}$ ). Treatments were administered intra-peritoneally daily for 28 days. Golgi staining technique investigated the number of dendritic spines. Cresyl violet staining method was used to determine the number of neurons in the hippocampal region CA1. Griess technique was assessed to determine serum nitrite oxide levels. Also, the ferric reducing/antioxidant power (FRAP) method was applied to determine the total antioxidant capacity. Results: Nicotine administration significantly increased the nitrite oxide level and decreased total antioxidant capacity. The number of neuronal dendritic spines, as well as neurons per se, also decreased, compared to the control group $(p<0.01)$. In all the members of the Curcumin and Nicotine + Curcumin groups, the number of neurons, neuronal dendritic spines and total antioxidant capacity increased significantly compared to the nicotine control group, while nitrite oxide level decreased significantly compared to the nicotine control group $(p<0.01)$. Conclusions: It seems that Curcumin administration improved hippocampal CA1 region injury in rats caused by Nicotine.
\end{abstract}

Key words: CA1, Curcuma longa, Nicotine

\section{INTRODUCTION}

Tobacco consumption has declined dramatically in industrialized countries over the past three decades due to raising awareness of the risks to health and effective control policies, while it has increased in developing countries over the same period ${ }^{1}$. Each cigarette has an average of 10-14 mg of nicotine ${ }^{2}$. Nicotine spreads rapidly into brain tissue through pulmonary circulation and within 10-20 seconds, attaches itself to the nicotinic acetylcholine receptors $(\mathrm{nAChRs})^{3}$. Nicotine in a cigarette is an alkaloid that passes through the blood-brain barrier and stimulates the mesolimbic dopamine system ${ }^{4}$. Nicotine can regulate brain neurotransmitters, including catecholamine, serotonin, glutamate, and Gamma-Aminobutyric Acid (GABA). This substance also reduces the activity of superoxide dismutase, glutathione peroxidase, and glutathione reductase in the hippocampus ${ }^{5}$. However, nicotine can induce oxidative stress in some organs, including the brain ${ }^{3}$. Pathologic changes associated with neuronal apoptosis have been reported due to the use of nico- tine $^{6}$. Cigarette smoking can cause hypoxia, cerebral ischemia, hemorrhage, atrophy, ataxia, cerebral infarction, and subarachnoid hemorrhage ${ }^{7}$. Also, nicotine can induce increased oxidative stress and neuronal apoptosis, destroy Deoxyribonucleic acid (DNA), produce reactive oxygen species (ROS), and increase the production of lipid peroxidation ${ }^{8}$. Nicotine seems to activate the areas of the brain that play an essential role in drug addiction and learning process ${ }^{9}$. Among the brain areas where nicotine has the greatest effect, is the mesocorticolimbic region (that contains nucleus accumbens), ventral tegmental area, the hippocampus, and the amygdala. In this region, the amygdala and hippocampus have structures that play an important role in the formation of long-term memory, and their function is associated with a stimulation reward system ${ }^{10}$. Hippocampus is a part of the limbic system and seems to be essential for the formation of various types of learning and memory ${ }^{11}$. Cornu Ammonis 1 (CA1) area, which belongs to the hippocampus, plays an essential role in converting short-term memory to long-term memory ${ }^{12}$. In recent years, an increase is seen in the use of herbal medicines 
for reducing the side effects of drug use ${ }^{13}$. For centuries, India and China have been using turmeric as an anti-inflammatory agent in the treatment of colic pain, toothache, chest pain, jaundice, anorexia, and menstrual problems ${ }^{14}$. The rhizome extract contains mainly curcumin and, to a lesser extent, desmethoxycurcumin, and bisdemethoxycurcumin ${ }^{11}$. Curcumin has antioxidant and anti-inflammatory properties ${ }^{15}$. The results of a study by Jayaprakasha et al. showed that in Alzheimer's experimental model, curcumin could improve memory via intravenous injection of streptozotocin $^{16}$. Curcumin can increase neurogenesis and improve cognitive processes in elderly female rats ${ }^{17}$. The results of the study by Mashayekhi et al. on various antioxidants showed that curcumin is much more potent in breaking down free radicals than vitamin E. In addition, it can protect the brain against lipid peroxidation and break down nitrite oxide (NO)-induced radicals ${ }^{18}$. Curcumin seems to prevent the effects of nicotine in the brain via the reduction of the oxidative stress mechanism. Considering effects of nicotine toxicity on the brain and the therapeutic properties of curcumin, the present study investigates the effects of curcumin on nicotineinduced toxicity in the hippocampus CA1 region of male rats and evaluates the antioxidant effect of curcumin on CA1 damage.

\section{MATERIALS - METHODS}

\section{Animals}

A total of 48 male Wistar rats) weighing 220-250 g (were purchased from the Pasteur Institute and transferred to the animal house in medical school. During the study, the animals were kept under standard conditions for 12-h light/12-h dark and $22 \pm 2{ }^{\circ} \mathrm{C}$, on a straw bed in special cages. Water and food were available to the animals ad libitum. Standard food was including plate and treated municipal water was used to feed the animals. All investigations were approved by the Ethics Committee of Kermanshah University of Medical Sciences and conformed to the ethical and human principles of research (ethics certificate No.1396.562) ${ }^{15}$.

\section{Study groups and treatment of animals}

Curcumin powder (Sigma, USA) with a chemical formula of $4-(\mathrm{OH})-3-\left(\mathrm{CH}_{3} \mathrm{O}\right)$ was dissolved in $0.9 \%$ normal saline solution to obtain relevant doses. The mixture of the solute and solvent was heated up to 70$80^{\circ} \mathrm{C}$. The heterogeneous mixture was filtered to get a homogenous solution of curcumin in normal saline. A vial of nicotine (Sigma, USA) with a dose of $0.5 \mathrm{mg}$ per $\mathrm{kg}$ of body weight was dissolved in $0.9 \%$ normal saline solution. Next, 48 male rats were randomly divided into 8 groups, and 6 rats were placed in each group. The first group (i.e., the normal control group) received normal saline through intra-peritoneal injection equivalent to the number of experimental groups. In the second group (i.e., the control group of nicotine), each animal received $0.5 \mathrm{mg} / \mathrm{kg}$ single dose course of nicotine, intraperitoneally. The solvent of nicotine was normal saline ${ }^{16}$. Group 3, 4, and 5 were treated with curcumin. In these groups, each animal received 10,30 , and $60 \mathrm{mg} / \mathrm{kg}$ of curcumin intra-peritoneally for 28 days at 10 a.m. Group 6, 7 and 8 were Nicotine + Curcumin administration groups, wherein each animal received a single dose of $0.5 \mathrm{mg} / \mathrm{kg}$ Nicotine in order to induce damage. Then, they received 10,30 , and $60 \mathrm{mg} / \mathrm{kg}$ of curcumin intraperitoneally for 28 days at $10 \mathrm{am}$ as previously described $^{8,12}$.

\section{Transcardiac perfusion}

The transcardiac method was used for fixation. Around $24 \mathrm{~h}$ after the last injection of the drug, animals were intra-peritoneally anesthetized with ketamine $70 \mathrm{mg} / \mathrm{kg}$ and diazepam $10 \mathrm{mg} / \mathrm{kg}$. The chest was opened in the midline. Following the completion of thoracotomy, the apex of the left ventricle was pierced, and a glass cannula of $1 \mathrm{~mm}$ diameter was inserted and fixed on ascending aorta. The pericardium and the right ventricle were cut. The left ventricle pathway was cut, and the ascending aorta was connected to a plastic tube via the glass cannula and descending aorta was clamped right above the diaphragm. The cannula linked to the normal saline solution was implanted into the aorta through an incision in the left ventricle. The descending aorta was fastened and, after washing the brain, the solution was removed through the incision made in the right atrium. Formalin 5\% and buffer phosphate $7 \%$ were inoculated into the brain by the cannula, and the brain was fixed in $15 \mathrm{~min}$. After perfusion, the brains were separated from the skull and stored in the same perfusion solution for three days as previously described ${ }^{11}$.

\section{Tissue preparing and Golgi methods}

The Golgi method was used to observe neuron dendrites in hippocampus CA1 region. The Golgi method was applied using potassium dichromate, followed by silver nitrate. After brain fixation, tissue blocks were submerged in 3\% potassium dichromate solution for 48 hours in a dark environment. The blocks were washed in $0.75 \%$ silver nitrate solution 


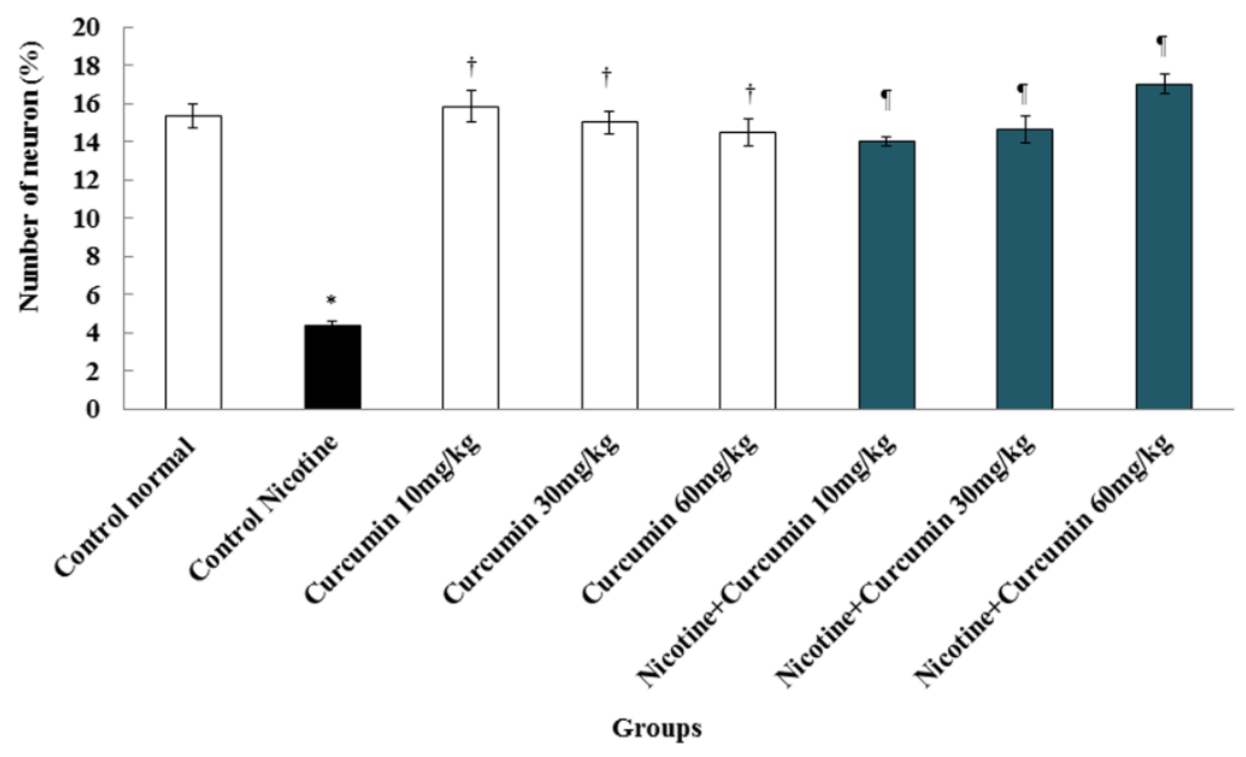

Figure 1: Effect of Nicotine, Curcumin, and Nicotine + Curcumin administration on the number of neurons in the CA1 region. *Significant decrease in the mean number of neurons in the Nicotine control group compared to the normal control group $(p<0.01)$; Significant increase in all Curcumin groups compared to the Nicotine control groups $(p<0.01)$; Significant increase in all Nicotine + Curcumin groups compared to the Nicotine and normal control groups $(p<0.01)$.

and then were submerged in the solution for 72 hours. Then, the tissues were washed in $1 \%$ silver nitrate solution. After that, preparing paraffin-embedded blocks were made, using the Automatic Tissue Processor. The steps of this process included fixation with $10 \%$ normal saline (for 72 hours), washing thoroughly under running water, dehydrating by raised doses of ethanol (50,60, 70, 80, 90 and 100\%, which included 3 min for each step and $100 \%$ ethanol step was repeated for three times), clearing by xylene (10 minutes for three times) and embedding in soft paraffin (three times, 15 min each time). At this stage, 5$\mu \mathrm{m}$ coronal histological thin sections were cut from paraffin-embedded blocks, undertaken by a microtome instrument (Leica RM 2125, Leica Microsystems Nussloch GmbH; Germany), and 5 sections per animal were chosen. For the unification of the section selection, the first section was the 4 th, and the last was the 24th ( 5 sections interval). Finally, the routine protocol for Golgi methods was implemented. At the end of the tissue processing, stained sections were mounted by entalan glue and assessed under Olympus BX-51T-32E01 research microscope, connected to a DP12 Camera with 3.34-million pixel resolution and Olysia Bio software (Olympus Optical Co. LTD, Tokyo, Japan) ${ }^{12}$.

\section{Cresyl violet method}

The Cresyl violet staining method was used to determine the number of live cells in the hippocampus CA1 region. Six rat heads from each group, and five tissue samples from each mouse were selected for staining. After creating $5 \mu \mathrm{m}$ cuts by microtome and performing tissue processing, the left hemispheres were stained, using Cresyl violet staining technique. Once the photo was prepared, the number of cells was counted per $1 \mathrm{~mm}^{2}$ area. On the slides, stained by means of Cresyl violet technique, the round cells without peak nose were considered as live cells ${ }^{19}$.

\section{Morphometrically technique}

On the slides, marked via Golgi staining method, completely stained neurons with cell bodies in the central part of the tissue sections, distant from the surrounding stained neurons were included in the study. The dendritic tree of pyramidal neurons was revealed through camera lucida with magnification = 750. The dendritic exclusion order from the cell body was used for counting dendritic sections. Additionally, the Sholl procedure was applied to assess the concentration of dendritic divisions. In the slips, marked via Cresyl violet method, the round cells without peak nose were considered as live cells. The slides were imaged by Motic microscope, and cells were counted by 


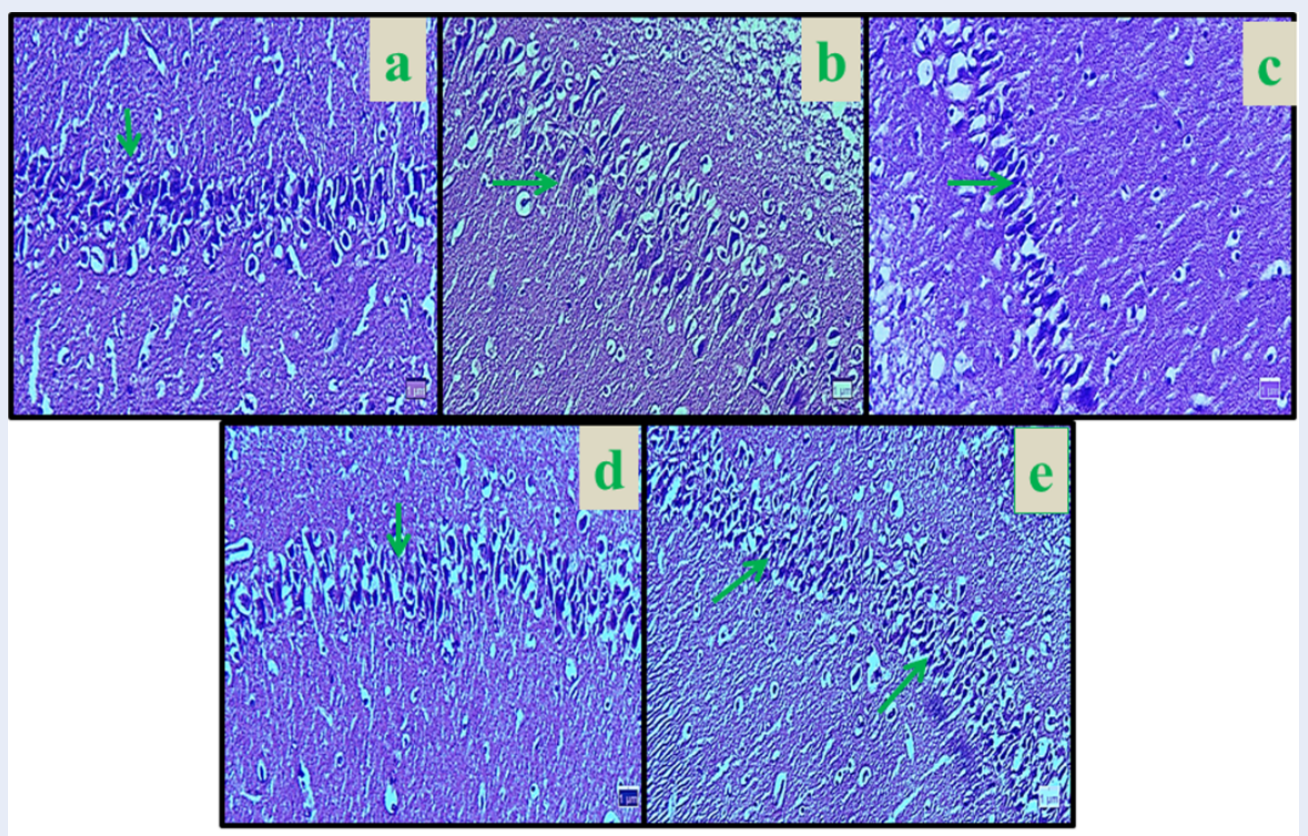

Figure 2: Microscopic images of CA1 region in male rats in different groups (5 $\mu \mathrm{m}$ thick sections, Cresyl violet staining, magnification: $\times$ 100). Micrograph of the $C A 1$ section in the normal control groups (a), the normal number of neurons in the CA1 region. Micrograph of the CA1section in Nicotine control group (b), decreased neurons cells due to the oxidative stress caused by Nicotine. Micrograph of the hippocampal region CA1section in Curcumin $(60 \mathrm{mg} / \mathrm{kg})$ group (c), the normal number of neurons. Micrograph of hippocampal region CA1section in Nicotine+ Curcumin $(30 \mathrm{mg} / \mathrm{kg})(\mathbf{d})$ and Nicotine+ Curcumin $(60 \mathrm{mg} / \mathrm{kg})(\mathbf{e})$ groups (d), normal number of neurons. Red arrows identifies pyramidal neuron cells.

Image J software $1.45^{11}$.

\section{Griess technique}

Griess technique uses zinc sulfate powder to eliminate the serum protein of the samples. In this study, zinc sulfate powder $(6 \mathrm{mg})$ was mixed with serum samples (400 $\mu \mathrm{l}$ ) and vortexed for $1 \mathrm{~min}$. The samples were centrifuged at $4{ }^{\circ} \mathrm{C}$ for $10 \mathrm{~min}$ at $12,000 \mathrm{rpm}$, and the supernatant was collected to measure nitrite oxide content. Briefly, $50 \mu \mathrm{l}$ of sample was added to 100 $\mu \mathrm{l}$ of Griess reagent (Sigma; USA), and the reaction mixture was incubated for $30 \mathrm{~min}$ at room temperature. Sodium nitrite $(0.1 \mathrm{M})$ was used for the standard curve, and increasing concentrations of sodium nitrite $(5,10,25,50,75$, and $100 \mu \mathrm{M})$ were prepared. The Greiss solution was added to all microplate containing sodium nitrite and supernatant and was read through an ELISA reader (stat fax100; the USA) at the wavelength of $540 \mathrm{~nm}^{20}$.

\section{Ferric reducing/antioxidant power (FRAP) method}

FRAP method was used to measure the total antioxidant capacity of the serum. In this technique, the abil- ity of the plasma in retaining ferric ions was measured. This process required a great quantity of $\mathrm{Fe}^{I I I}$. A blue stain was formed when the compound of $\mathrm{Fe}^{I I I}$-TPTZ in acidic $\mathrm{pH}$ returned to $\mathrm{Fe}^{I I}$ and absorption at the maximum wavelength of $600 \mathrm{~nm}$. The factor defining the speed of $\mathrm{Fe}^{I I}$-TPTZ and the blue color was the only vitalizing power of the sample. Total antioxidant capacity values are strategized by means of a standard curve with diverse concentrations of iron sulfate ${ }^{21}$.

\section{Statistical analysis}

Kolmogorov-Smirnov test was first conducted to confirm the data compliance of the normal distribution. One-way analysis of variance (one-way ANOVA) was used for statistical analysis, and Tukey post hoc test was used to determine the difference between the groups. SPSS 16 was used for data analysis; the results were expressed as mean \pm standard error, and $p$ $<0.05$ was considered statistically significant.

\section{RESULTS}

\section{Neurons number}

The number of neurons in the hippocampal region CA1 showed a significant decrease in Nicotine control 


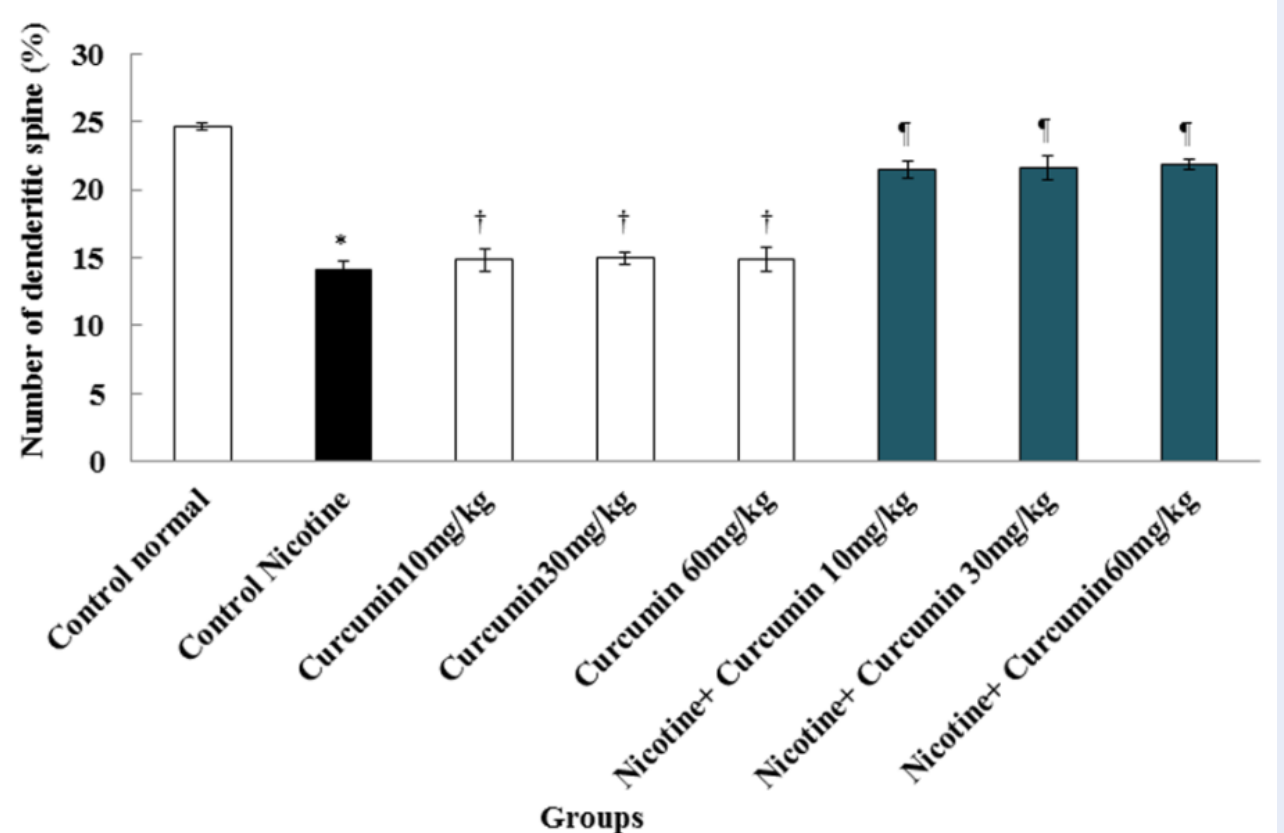

Figure 3: Comparison of Nicotine, saline and Curcumingroups at the number of dendritic spines in hippocampal region CA1. *Significant decrease in the Nicotine control group compared to the normal control group $(p<0.01)$. Significant increase in all Curcumin groups compared to the Nicotine control group $(p<0.01)$. Significant increase for all Nicotine+ Curcumin groups compared to the Nicotine and normal control groups $(p<0.01)$.

group compared to the normal control group $(8.33 \%)$ $(p<0.01)$. The mean number of neurons was not significantly different in all Curcumin groups compared to the normal control group $(p>0.05)$. The mean of pyramidal neurons increased significantly in Curcumin $($ dose $10 \mathrm{mg} / \mathrm{kg}=18.83 \%$, dose $30 \mathrm{mg} / \mathrm{kg}=$ $19 \%$, and dose $60 \mathrm{mg} / \mathrm{kg}=19.50 \%$ ), and Nicotine + Curcumin $($ dose $10 \mathrm{mg} / \mathrm{kg}=14 \%$, dose $30 \mathrm{mg} / \mathrm{kg}=$ $14.66 \%$, and dose $60 \mathrm{mg} / \mathrm{kg}=14 \%$ ) in all doses compared to the Nicotine control group $(p<0.01)$. Also, the average number of pyramidal neurons decreased significantly in all Nicotine + Curcumin groups (dose $10 \mathrm{mg} / \mathrm{kg}=14.12 \%$, dose $30 \mathrm{mg} / \mathrm{kg}=15.16 \%$, and dose $60 \mathrm{mg} / \mathrm{kg}=14.61 \%$ ) compared to the normal control group $(p<0.01)$ (Figure 1 and Figure 2).

\section{Dendritic spines}

The mean number of neuronal dendritic spines in experimental groups showed a significant decrease between normal control group and Nicotine control group $(7.13 \%)(p<0.01)$. The mean number of neuronal dendritic spines was not significant in all Curcumin groups compared to the normal control group ( $\mathrm{p}>0.05$ ). In the Curcumin (dose $10 \mathrm{mg} / \mathrm{kg}=$ $14.85 \%$, dose $30 \mathrm{mg} / \mathrm{kg}=14.96 \%$, and dose $60 \mathrm{mg} / \mathrm{kg}$ $=14.93 \%)$ and Nicotine + Curcumin groups (dose 10 $\mathrm{mg} / \mathrm{kg}=11.50 \%$, dose $30 \mathrm{mg} / \mathrm{kg}=11.66 \%$, and dose $60 \mathrm{mg} / \mathrm{kg}=11.83 \%$ ), the mean number of neuronal dendritic spines increased significantly in all treated groups compared with the nicotine control group $(p$ $<0.01$ ). Furthermore, mean number of neuronal dendritic spines decreased significantly in all Nicotine + Curcumin groups (dose $10 \mathrm{mg} / \mathrm{kg}=11.50 \%$, dose 30 $\mathrm{mg} / \mathrm{kg}=11.66 \%$, and dose $60 \mathrm{mg} / \mathrm{kg}=11.83 \%) \mathrm{com}-$ pared to the normal control group $(p<0.01)$ (Figure 3 and Figure 4).

\section{Nitrite oxide}

The results of blood serum NO measurement showed a significant increase in Nicotine control group compared to normal control group $(404.285 \mu \mathrm{m})(p<$ 0.01). Mean nitrite oxide in the blood serum was not significant different in all Curcumin groups compared to the normal control group ( $p>0.05$ ). Also, the mean of nitrite oxide levels in blood serum declined significantly in Curcumin (dose $10 \mathrm{mg} / \mathrm{kg}=$ $190.61 \mu \mathrm{m}$, dose $30 \mathrm{mg} / \mathrm{kg}=193.83 \mu \mathrm{m}$, and dose $60 \mathrm{mg} / \mathrm{kg}=190.69 \mu \mathrm{m})$ and Nicotine + Curcumin groups $($ dose $10 \mathrm{mg} / \mathrm{kg}=309.69 \mu \mathrm{m} \mu \mathrm{m}$, dose 30 $\mathrm{mg} / \mathrm{kg}=295.88 \mu \mathrm{m} \mu \mathrm{m}$, dose $60 \mathrm{mg} / \mathrm{kg}=299.58 \mu \mathrm{m}$ $\mu \mathrm{m})$ in all doses compared to the Nicotine control group $(p<0.01)$ (Figure 5). 


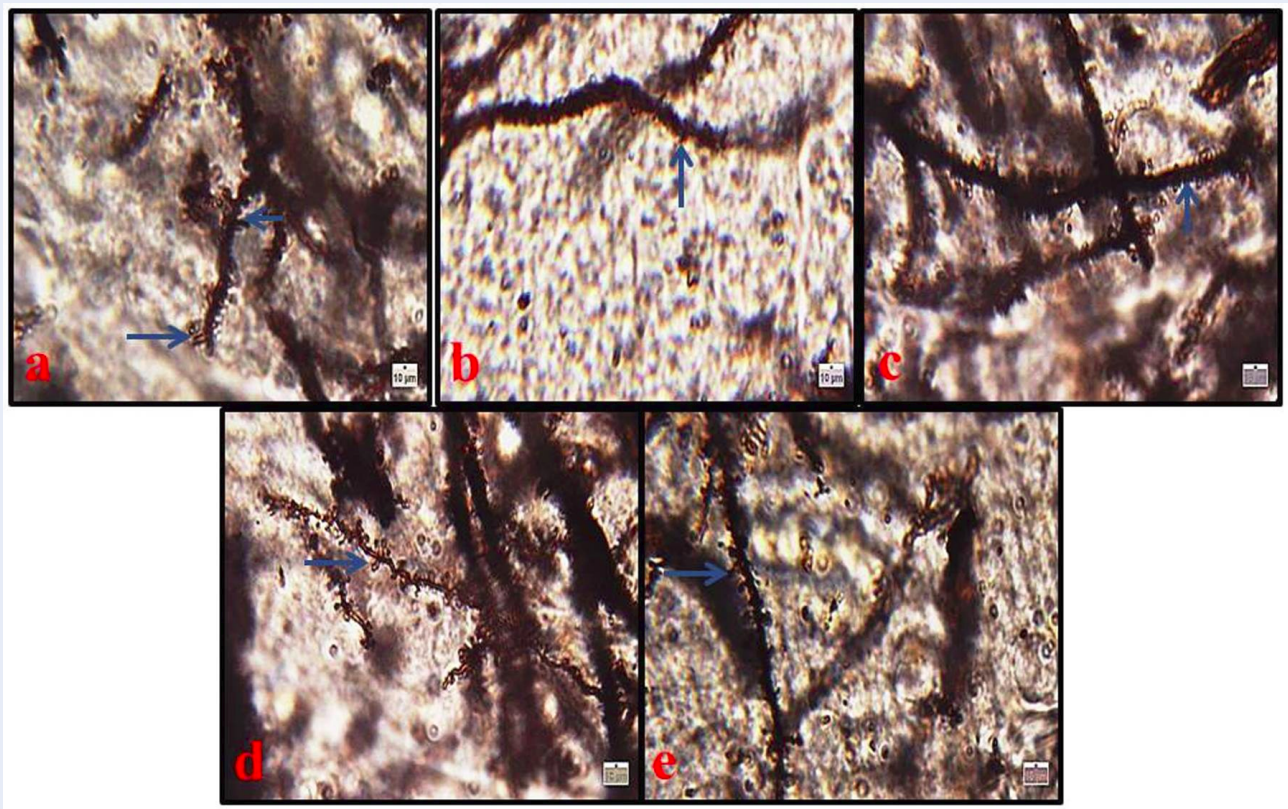

Figure 4: Microscopic images of neuronal dendritic spines in hippocampal region CA1 in male rats in different groups (Five-micron thick sections, Golgi staining, magnification: $\times \mathbf{1 0 0}$ ). Micrograph of the CA1 section in the normal control group (a), normal structure. Micrograph of the hippocampal region CA1 section in Nicotine control group (b), decreased number of dendritic spines due to the oxidative stress caused by Nicotine. Micrograph of the hippocampal region CA1 section in Curcumin $(60 \mathrm{mg} / \mathrm{kg})$ group (c), normal structure; Micrograph of CA1 section in Nicotine + Curcumin (30 mg/kg) group (d) and (60 mg/kg) (d) groups, normal structure. Blue arrows identifies neuronal dendritic spines.

\section{Total antioxidant capacity}

The results showed that total antioxidant capacity serum level reduced significantly in the Nicotine control group compared to the normal control group ( $p$ $<0.01$ ). The total antioxidant capacity level enhanced significantly in all Curcumin (dose $10 \mathrm{mg} / \mathrm{kg}=2.09$ $\mathrm{mmol} / \mathrm{i}$, dose $30 \mathrm{mg} / \mathrm{kg}=2.03 \mathrm{mmol} / \mathrm{i}$, dose $60 \mathrm{mg} / \mathrm{kg}$ $=2.04 \mathrm{mmol} / \mathrm{i}$ ) and nicotine + Curcumin groups (dose $10 \mathrm{mg} / \mathrm{kg}=1.24 \mathrm{mmol} / \mathrm{i}$, dose $30 \mathrm{mg} / \mathrm{kg}=1.28$ $\mathrm{mmol} / \mathrm{i}$, dose $60 \mathrm{mg} / \mathrm{kg}=1.31 \mathrm{mmol} / \mathrm{i})$ compared to the nicotine control group $(p<0.01)$ (Figure 6).

\section{DISCUSSION}

Nicotine causes a number of implications and side effects by affecting the central and peripheral nervous system. Regarding dosage, mode of application, and species, nicotine can affect an individual's behavior. Ventral hippocampal $\alpha 4 \beta 2$ blockade - induced working memory deficits are reversed by chronic systemic nicotine treatment, while ventral hippocampal $\alpha 7$ blockade-induced working memory deficits were not reversed by the same nicotine regimen ${ }^{6}$. Temporal lobe and hippocampal organization are involved in transferring short-term memory to longterm memory ${ }^{11}$. The present study was aimed to investigate the effects of curcumin on nicotine-induced disorders in the hippocampus CA1 region. The results of the current study showed that the number of neurons and dendritic thorns decreased significantly in the nicotine control group compared to the normal control group. In nicotine + curcumin groups, there was a significant increase in the number of dendritic thorns compared to the nicotine control group. The results may indicate the control of apoptosis and neuro-degeneration by administering different doses of curcumin. The results of Tewari et al. were consistent with those of the present study that showed nicotine could damage the cells in the hippocampus by increased protein accumulation in the membrane and reduced cell size ${ }^{22}$. Similarly, based on the results of the current study, nicotine could decrease the number of neurons significantly in the hippocampus 


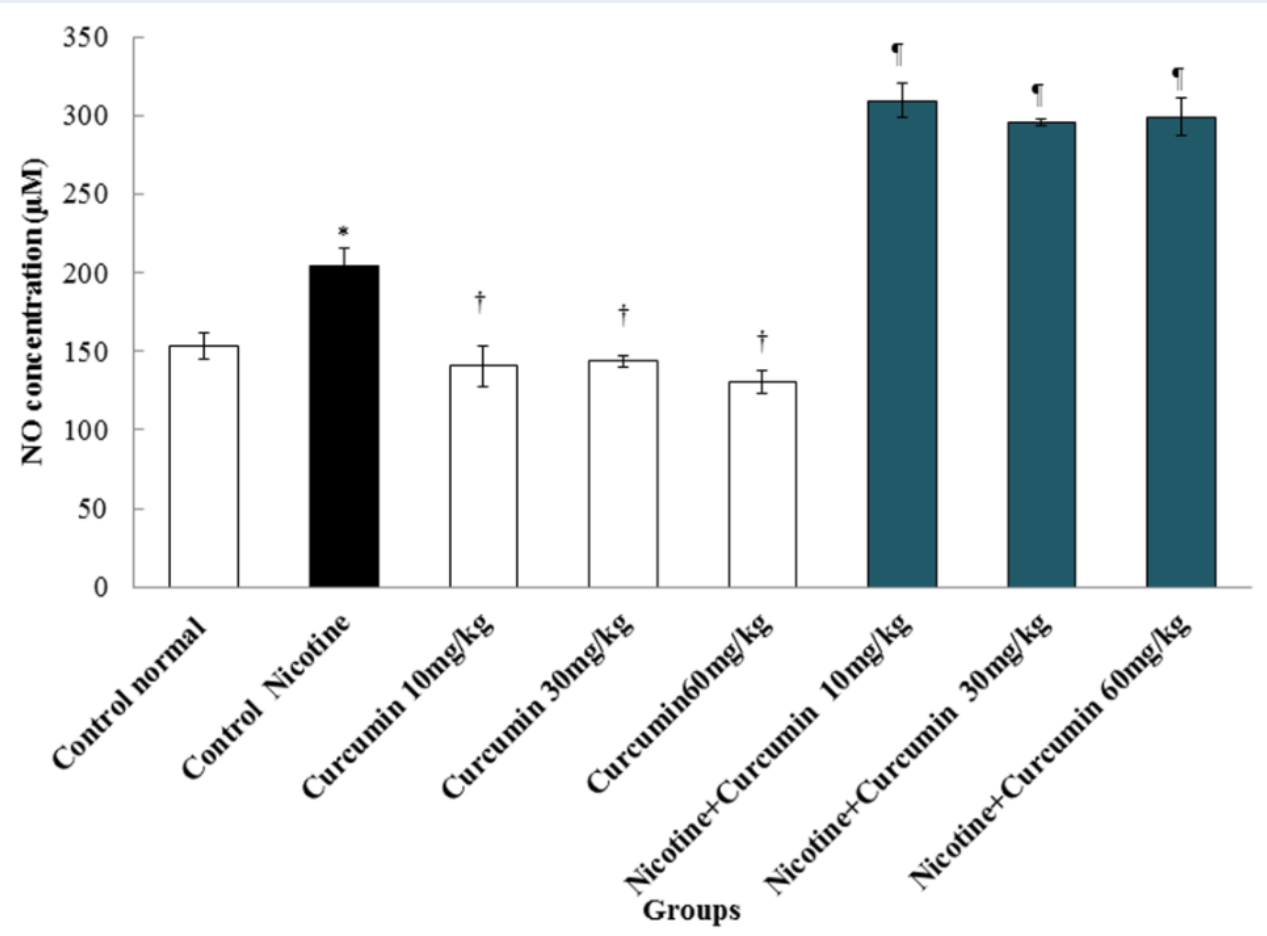

Figure 5: Effects of Curcumin, Nicotine, and Nicotine + Curcumin on the mean No levels. ${ }^{*}$ Significant increase of No in the Nicotine control group compared to the normal control group $(p<0.01)$. Significant decrease in all Curcumin groups compared to the Nicotine control group $(p<0.01)$. Significant decrease in all Nicotine + Curcumin groups compared to the Nicotine control group $(p<0.01)$.

due to damaging the cells. It seems that nicotine induces oxidative stress and, consequently, the production of free radicals such as superoxide and hydroxyl radicals can cause cell damage ${ }^{8}$. Generated free radicals following oxidative stress induction may have the potential to damage cellular compositions, including proteins, lipids, and DNA ${ }^{20}$. Equally, in the current study, nicotine could decrease the number of neurons and dendritic thorns in the hippocampus due to oxidative stress caused by administration of nicotine. Exposure to nicotine can also increase the production of ROS and peroxidation of lipids, and decrease the level of GSH antioxidant enzymes ${ }^{6}$. The brain is one of the most important organs in the body, which consumes a large amount of oxygen. Lipid in the membrane of nerve cells has a high content of oxidized unsaturated fatty acids ${ }^{12}$. Therefore, it seems that nicotine can produce ROS via P-450 enzyme and, by producing oxidative stress, cause the destruction of the nucleus in neurons ${ }^{5}$. Given that dendritic thorns play a major role in synaptic transmission, it is not surprising that many brain diseases are associated with changes in the morphology and density of dendritic thorns ${ }^{12}$. Dendrite thorns are involved in memory as an exon and dendrites interface ${ }^{14}$. Nicotine can reduce the length of dendrites and the number of dendritic thorns in nucleus accumbens by affecting neurotrophic factors in the striatum ${ }^{23}$. The results of the study by Brown et al. showed that nicotine injections with a dose of $0.7 \mathrm{mg} / \mathrm{kg}$ could reduce the length of dendrites and the number of dendritic thorns; which is consistent with the results of our study ${ }^{24}$. It seems that nicotine can destroy dendritic cells. Similarly, in the current study, due to oxidative stress, nicotine could decrease the number of neurons and dendritic thorns in the hippocampus horns by $\beta 2$-nAChRs deactivation in postsynaptic cells in the hippocampus region $^{25}$. Moreover, nicotine can reduce the number of thorns by deactivating $\alpha 4 \beta 2$-nAChRs in the presynaptic membrane and by disrupting the release of glutamate neurotransmitters ${ }^{26}$. It seems that nicotine reduces the number of dendritic thorns in two ways. One way is the regulation of glutamatergic synapses on pyramidal neurons. This mechanism is mainly based on the activity of $\alpha 4 \beta 2 \mathrm{nAChRs}$ on presynaptic glutamate terminus. Another mechanism focuses on the activity of GABA in the internal neurons or interneurons ${ }^{27}$. Curcumin is a neutralizer 


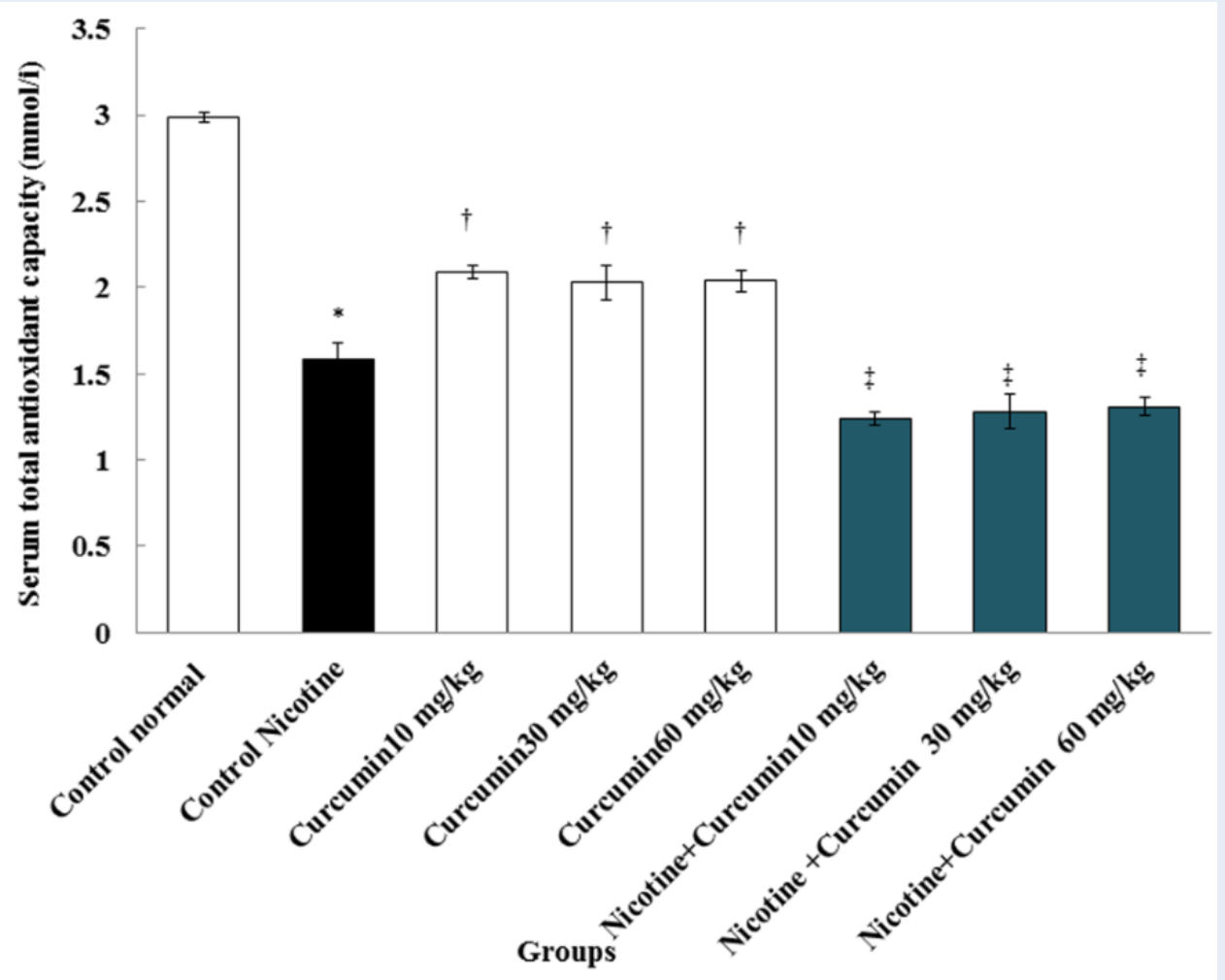

Figure 6: Comparison of total antioxidant capacity in Nicotine, and normal control and Curcumin and Nicotine + Curcumin groups. * Significant increase in Nicotine control group compared to the normal control group $(p$ $<0.01)$. Significant increase in all Curcumin groups compared to the Nicotine control group $(p<0.01)$. Significant increase in all Nicotine + Curcumin groups compared to the Nicotine control group $(p<0.01)$.

of reactive oxygen species ROS, which has the potential to destroy oxidative stress and prevents lipid peroxidation ${ }^{6}$. The results of the study by Shin et al. confirmed those of the present study that curcumin could prevent cell death from kainic acid due to oxidative stress in the hippocampus ${ }^{28}$. Curcumin seems to inhibit lipid peroxidation of quinolinic acid and controls the production of cyanide-induced superoxide in the brain, suggesting the protective properties of curcumin. In addition, nicotine treatment increased lipid peroxidation and the levels of GSH, IL$1 \beta$, TNF- $\alpha$, and Bax, while reducing Bcl-2, P-CREB, and BDNF levels in the hippocampus ${ }^{29}$. Curcumin has been shown to significantly improve spatial memory impairment induced by HIV-1 gp120 V3 in rats, but the electrophysiological mechanism remains unknown $^{30}$. The results of a study by Pan et al. are in line with the results of the present study, which showed that curcumin improves learning and memory in mice and can increase neuroprotective effects in Alzheimer's modal rats ${ }^{31}$. Curcumin can reduce neuropathological changes in the hippocampus and control apoptosis by increasing the density of Bcl2 protein ${ }^{32}$. The present study showed a significant increase in serum NO levels in the nicotine control group compared to the normal control group. In all nicotine + curcumin groups, there was a significant decrease in serum NO levels in comparison to the nicotine control group. NO is a free radical, and that can regulate angiogenesis, apoptosis, cell cycle, invasion, and metastasis in cells. NO plays a key role in the destruction of myelin in the central nervous system ${ }^{11}$. Nicotine can stimulate nicotinic receptors in the brain and increase glutamate release and NMDA activation. The activation of NMDA may increase the formation of nitric oxide in the hippocampus ${ }^{33}$. The results of a study by Keser et al. revealed that the exposure to nicotine increased the activity of NO in the frontal cortex in the mouse brain. This result confirms the results of the present study ${ }^{34}$. Also, the results of Salahshoor et al. are consistent with those of the present study, which shows that curcumin prescription significantly decreased the serum level of NO in the blood serum of mice ${ }^{8}$. The results of this study 
showed that there was a significant decrease in total antioxidant levels in the nicotine control group compared to the normal control group. In all nicotine + curcumin groups, there was a significant decrease in serum total antioxidant levels in comparison to the nicotine control group. The results of the study by Zhuo et al. showed that total antioxidant level was reduced significantly in smokers in proportion to nonsmokers; which is consistent with the results of a similar study ${ }^{35}$. It seems that the reduction of total antioxidant capacity in plasma of smokers has led to an increase in the production of free radicals ${ }^{36}$. The reduction in total antioxidant capacity levels in this study shows the effects of oxidative stress from nicotine on the hippocampal neurons. This result is expressed as growth in the levels of ROS, lipid peroxidation, and a reduction in the action of antioxidant enzymes such as total antioxidant capacity ${ }^{37}$. Curcumin, via activation of P-CREB/BDNF signaling pathway, confers neuroprotection against nicotine-induced inflammation, apoptosis, and oxidative stress. In contrast, various doses of curcumin attenuated nicotine-induced apoptosis, oxidative stress, and inflammation, while elevating P-CREB and BDNF levels. Thus, curcumin, via activation of $\mathrm{P}-\mathrm{CREB} / \mathrm{BDNF}$ signaling pathway, confers neuroprotection against nicotine-induced inflammation, apoptosis, and oxidative stress ${ }^{38}$. In the present study, improved levels of total antioxidant capacity in rats treated with curcumin highlighted the antioxidant and anti-lipid peroxidation effects of curcumin. An increase in total antioxidant levels due to the administration of nicotine in the present work may suggest the positive impact of curcumin on magnified antioxidant effects, the inhibition of nicotineinduced inflammation and the destruction process on neurons in the brain. Curcumin can inhibit nitric oxide by reducing the activity of the nuclear factorkappa $\beta(\mathrm{NF}-\mathrm{K} \beta)^{39}$. Our study had certain limitations, such as the lack of detecting antioxidant levels in the curcumin. There was a lack of references about the effect of plant or extract in CA1 region, and death of some animals due to nicotine administration in this study was an important limitation. Hence, prospective studies should be taken for the detailed association of the molecular interaction between Curcumin and $\mathrm{CA} 1$ region in rats.

\section{CONCLUSION}

The current study indicated that curcumin could recover some CA1 injuries significantly, which is contrary to the destructive properties of nicotine in rats. It appears that curcumin provides protection against oxidative stress resulting from nicotine. Such an ability of curcumin might be due to its strong potential antioxidant attributes. As a result, it leads to CA1 tissue recovery and prevention of nicotine adverse effects on total antioxidant capacity, nitric oxide, number of neurons, and dendritic spines, as evidenced in the above mentioned examination of the male rats. However, supplementary studies are essential to describe its molecular mechanism.

\section{ABBREVIATIONS}

CA1: Cornu Ammonis 1

DNA: Deoxyribonucleic acid

FRAP: Ferric reducing/antioxidant power

GABA: Gamma-Aminobutyric Acid

nAChRs: nicotinic acetylcholine receptors

NO: Nitrite oxide

ROS: Reactive oxygen species

\section{AUTHOR CONTRIBUTIONS}

CJ conceived and designed the experiments, CJ and SMR revised the manuscript, SR and ARB analyzed the data and MRS wrote the paper. All authors read and confirmed the publication of the article.

\section{FINANCIAL SUPPORT AND SPONSORSHIP}

We are grateful to the Research Council of Kermanshah University of Medical Sciences (No: 1396.562) for their financial support.

\section{COMPETING INTERESTS}

The authors declare they have no competing interests.

\section{REFERENCES}

1. Sharapova SR, Singh T, Agaku IT, Kennedy SM, King BA Patterns of E-cigarette Use Frequency-National Adult Tobacco Survey. American Journal of Preventive Medicine. 2018;54:284-288. PMID: 29129463. Available from: 10.1016/j. amepre.2017.09.015.

2. Pacek LR, Oliver JA, Sweitzer MM, Mcclernon FJ. Young adult dual combusted cigarette and e-cigarette users anticipated responses to a nicotine reduction policy and menthol ban in combusted cigarettes. Drug alcohol dependence. 2019;194:40-44. PMID: 30399498. Available from: 10.1016/j. drugalcdep.2018.10.005.

3. Filbey FM, Gohel S, Prashad S, Biswal BB. Differential associations of combined vs. isolated cannabis and nicotine on brain resting state networks. Brain Structure and Function. 2018;7:3317-3326.

4. Kimura I, Dohgu S, Takata F, Matsumoto J, Kawahara Y, Nishihira $\mathrm{M}$, et al. Activation of the $\alpha 7$ nicotinic acetylcholine receptor upregulates blood-brain barrier function through increased claudin-5 and occludin expression in rat brain endothelial cells. Neuroscience Letters. 2019;694:9-13. PMID: 30452951. Available from: 0.1016/j.neulet.2018.11.022. 
5. Jalili C, Ahmadi S, Roshankhah S, Salahshoor M, et al. Effect of genistein on reproductive parameter and serum nitric oxide levels in morphine-treated mice. International Journal of Reproductive Biomedicine (Yazd). 2016;14:95-102. PMID: 27200423. Available from: 10.29252/ijrm.14.2.95.

6. Jalili C, Salahshoor MR, Khademi F, Jalili $\mathrm{P}$, Roshankhah $\mathrm{SH}$ Morphometrical Analysis of the Effect of Nicotine Administration on Brains Prefrontal Region in Male Rat. International Journal of Morphology. 2014;32:761-766. Available from: 10.4067/S0717-95022014000300003.

7. Fricker M, Goggins BJ, Mateer S, Jones B, Kim RY, Gellatly SL. Chronic cigarette smoke exposure induces systemic hypoxia that drives intestinal dysfunction. JCl insight. 2018;3:94040. PMID: 29415878. Available from: 10.1172/jci.insight.94040.

8. Salahshoor MR, Mohamadian S, Kakabaraei S, Roshankhah S, Jalili C. Curcumin Improves liver Damage in Male Mice Exposed to Nicotine. Journal of Traditional and Complementary Medicine. 2016;6:176-183. PMID: 27114942. Available from: 10.1016/j.jtcme.2014.11.034

9. Kuo YH, Huang TT, Chou EY, Chiang YC, Hoffer YH, Miller BJ, et al. Effect of traumatic brain injury on nicotine-induced modulation of dopamine release in the striatum and nucleus accumbens shell. Oncotarget. 2018;9:10016-10028. PMID: 29515787. Available from: 10.18632/oncotarget.24245.

10. Changeux JP. Nicotine addiction and nicotinic receptors: lessons from genetically modified mice. Nature Reviews Neuroscience. 2010;11:389-401. PMID: 20485364. Available from: $10.1038 / \mathrm{nrn} 2849$.

11. Jalili C, Salahshoor MR, Pourmotabbed A, Moradi S, Motaghi $M$, and ASD. The Effects of Aqueous Extract of Boswellia Serrata on Hippocampal Region CA1 and learning deficit in kindled Rats. Research in pharmaceutical science. 2014;9:351358. Research in pharmaceutical science 9. PMID: 25657807.

12. Moradi S, Pourmotabbed A, Salahshoor MR, Jalili C, Motaghi $M$, Kakebaraei S. The Morphometric Effects of Aqueous Extract of Boswellia Serrata on Hippocampal Region CA1 in kindled Rats. Int J Morphol. 2014;32:1271-1276.

13. Wink M. Modes of action of herbal medicines and plant secondary metabolites. Medicines. 2015;2:251-286. PMID: 28930211. Available from: $10.3390 /$ medicines 2030251

14. Oyarce P, De, Meester B, Fonseca F, De, Vries L, et al. Introducing curcumin biosynthesis in Arabidopsis enhances lignocellulosic biomass processing. Nature Plants. 2019;5:225-237. PMID: 30692678. Available from: 10.1038/s41477-018-0350-3.

15. Jalili C, Salahshoor MR, Jalili F, Kakaberaei S, Akrami A, Sohrabi M. Therapeutic effect of resveratrol on morphine-induced damage in male reproductive system of mice by reducing nitric oxide serum level. International Journal of Morphology. 2017;35:1342-1347. Available from: 10.4067/S071795022017000401342.

16. Jayaprakasha GK, Jagan, Mohan, Rao L, Sakariah KK. Improved HPLC method for the determination of curcumin, demethoxycurcumin, and bisdemethoxycurcumin. Journal of agricultural and food chemistry. 2002;50:3668-3672. PMID: 12059141. Available from: 10.1021/jf025506a.

17. Belviranl M, Okudan N, Atalk KEN, Öz M. Curcumin improves spatial memory and decreases oxidative damage in aged female rats. Biogerontology. 2013;14:187-196. PMID: 23609199. Available from: 0.1007/s10522-013-9422-y.

18. Antosiak A, Milowska K, Maczynska K, Rozalska S, Gabryelak T. Cytotoxic activity of genistein-8-C-glucoside form Lupinus luteus $L$. and genistein against human SK-OV-3 ovarian carcinoma cell line. Medicinal Chemistry Research. 2017;26:64-73. PMID: 28111515. Available from: 10.1007/s00044-016-1725-5.

19. Jalili $C$, Salahshoor MR, Khani F, Roshankhah $\mathrm{SH}$. Protective Effect of Curcumin against Nicotine-induced Damage on Reproductive Parameters in Male Mice. International Journal of Morphology. 2014;32:869-874. Available from: 10.4067/ S0717-95022014000300017.

20. Salahshoor MR, Roshankhah S, Hosseni P, Jalili C. Genistein Improves Liver Damage in Male Mice Exposed to Morphine. Chinese Medical Journa. 2018;131:1598-1604. PMID:
29941714. Available from: 10.4103/0366-6999.235117.

21. Ghorbani R, Mokhtari T, Khazaei M, Salahshoor MR, Jalili $C$, Bakhtiari M. The effect of walnut on the weight, blood glucose and sex hormones of diabetic male rats. International Journal of Morphology. 2014;32:858-8209. Available from: 10.4067/S0717-95022014000300015.

22. Tewari A, Misra R. Neurochemical Effects of Nicotine on Albino Rats. Brain Arch Neurosci. 2014;1:51-54. Available from: 10. 5812/archneurosci.9942.

23. Androuin A, Potier B, Ngerl UV, Cattaert D, Danglot $L$, Thierry $M$, et al. Evidence for altered dendritic spine compartmentalization in Alzheimers disease and functional effects in a mouse model. Acta Neuropathologica. 2018;25:1-6. PMID: 29696365. Available from: 10.1007/s00401-018-1847-6.

24. Brown R. Nicotine sensitization increases dendritic length and spine density in the nucleus accumbens and cingulate cortex. Brain Research. 2001;899:94-100. PMID: 11311869. Available from: 10.1016/S0006-8993(01)02201-6.

25. Eftekhari A, Ahmadian E, Panahi-Azar V, Hosseini H, Tabibiazar M, S Maleki D. Hepatoprotective and free radical scavenging actions of quercetin nanoparticles on aflatoxin B1induced liver damage: In vitro/in vivo studies. Artificial Cells, Nanomedicine, and Biotechnology. 2018;46:420-420. PMID 28423950. Available from: 10.1080/21691401.2017.1315427.

26. Oda A, Nakagomi S. Nicotine induces dendritic spine remodeling in cultured hippocampel neurons. J Neurochemistry. 2014;128:246-255. PMID: 24117996. Available from: $10.1111 /$ jnc. 12470 .

27. Zambrano CA, Escobar D, Ramos-Santiago T, Bollinger I, Stitzel J. Serine residues in the $\alpha 4$ nicotinic acetylcholine receptor subunit regulate surface $\alpha 4 \beta 2 *$ receptor expression and clustering. Biochemichal Pharmacology. 2019;159:64-73. PMID: 30414940. Available from: 10.1016/j.bcp.2018.11.008.

28. Shin HJ, Son E, Lee DH, Kim HJ, Kang SS, Cho GJ, et al. Curcumin attenuate the Kainic acid Induced hippocampal cell death in mice. Neuroscience letters. 2007;416:49-54. PMID: 17300872. Available from: 10.1016/j.neulet.2007.01.060.

29. Bartos M, Gumilar F, Gallegos CE, Bras C, Dominguez S, Mnaco $\mathrm{N}$. Alterations in the memory of rat offspring exposed to low levels of fluoride during gestation and lactation: Involvement of the 7 nicotinic receptor and oxidative stress. Reproductive Toxicology. 2018;81:108-114. PMID: 30009953. Available from: 10.1016/j.reprotox.2018.07.078.

30. Shen LL, Jiang ML, Liu SS, Cai MC, Hong ZQ, Lin LQ. Curcumin improves synaptic plasticity impairment induced by HIV1gp120 V3 loop. Neural Regeneration Research. 2015;10:925931. PMID: 26199609. Available from: 10.4103/1673-5374. 158358.

31. Pan R, Lu DX, Dong J. Curcumin improves learning and memory ability and its neuroprotective mechanism in mice. Chinese Medical Journal. 2008;121:832-839. PMID: 18701050. Available from: 10.1097/00029330-200805010-00015.

32. Muthuraman A, Thilagavathi L, Jabeen S, Ravishankar SB, Ahmed SS, George T. Curcumin prevents cigarette smoke extract induced cognitive impairment. Frontiers in Bioscience. 2019;11:109-120. Elite Edition. Available from: 10.2741/ e850PMID:30468642.

33. Piri M, Nasehi M, Shahab Z, Zarrindast MR. The effects of nicotine on nitric oxide induced anxiogenic-like behaviors in the dorsal hippocampus. Neuroscience Letters. 2012;528:93-98. PMID: 22985517. Available from: 10.1016/j.neulet.2012.08.074.

34. Keser A, Nesil T, Kanit L, Pogun S. Brain nitric oxide metabolites in rats preselected for nicotine preference and intake. Neuroscience Letters. 2013;545:102-106. PMID: 23643897. Available from: 10.1016/j.neulet.2013.04.027.

35. Zhuo L, Liao M, Zheng L, He M, Huang Q, Wei L. Combination therapy with taurine, epigallocatechin gallate and genistein for protection against hepatic fibrosis induced by alcohol in rats. Biological and Pharmaceutical Bulletin. 2012;35:18021810. PMID: 23037169. Available from: 10.1248/bpb.b1200548 . 
36. Isik B, Ceylan A, Isik R. Oxidative stress in smokers and nonsmokers. Inhalation Toxicology. 2007;19:767-769. PMID: 17613085. Available from: 10.1080/08958370701401418.

37. Schreiber R, Buchholz B, Kraus A, Schley G, Scholz J, Ousingsawat J. Lipid Peroxidation Drives Renal Cyst Growth In Vitro through Activation of TMEM16A. Journal of American Society of Nephrology. 2019;30:228-242. PMID: 30606785. Available from: 10.1681/ASN.2018010039.

38. Motaghinejad M, Motevalian M, Fatima S, Faraji F, Mozaffari S. The Neuroprotective Effect of Curcumin Against Nicotine-
Induced Neurotoxicity is Mediated by CREB-BDNF Signaling Pathway. Neurochemichal research. 2017;42:2921-2932. Available from: 10.1007/s11064-017-2323-8.

39. Akaishi T, Abe K. cnb-001, a synthetic pyrazole derivative of curcumin, suppresses lipopolysaccharide-induced nitric oxide production through the inhibition of Nf-b and p38 Mapk pathways in microglia. European Journal of Pharmacology. 2018;819:190-197. PMID: 29221948. Available from: 10.1016 j.ejphar.2017.12.008.

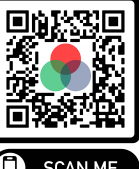

